\title{
Papers
}

\section{Treatment of paediatric malaria during a period of drug transition to artemether-lumefantrine in Zambia: cross sectional study}

\author{
Dejan Zurovac, Mickey Ndhlovu, Alexander K Rowe, Davidson H Hamer, Donald M Thea, Robert W Snow
}

\begin{abstract}
Objective To evaluate treatment practices for uncomplicated malaria after the policy change from chloroquine to sulfadoxine-pyrimethamine and to artemether-lumefantrine in Zambia.

Design Cross sectional survey.

Setting Outpatient departments of all government and mission facilities in four districts in Zambia.

Participants 944 children with uncomplicated malaria seen by 103 health workers at 94 health facilities.

Main outcome measures Antimalarial prescriptions in accordance with national guidelines and influence of factors on health workers' decision to prescribeartemether-lumefantrine. Results Artemether-lumefantrine, sulfadoxine-pyrimethamine, and chloroquine were available, respectively, at 48 (51\%), 94 $(100 \%)$, and $71(76 \%)$ of the 94 facilities. Of 944 children with uncomplicated malaria, only one child $(0.1 \%)$ received chloroquine. Among children weighing less than $10 \mathrm{~kg}$, sulfadoxine-pyrimethamine was commonly prescribed in accordance with guidelines (439/550, 79.8\%). Among the children weighing $10 \mathrm{~kg}$ or more, sulfadoxine-pyrimethamine was commonly prescribed $(266 / 394,68 \%)$, whereas recommended artemether-lumefantrine was prescribed for only 42/394 (11\%) children. Among children weighing $10 \mathrm{~kg}$ or more seen at facilities where artemether-lumefantrine was available, the same pattern was observed:

artemether-lumefantrine was prescribed for only 42/192 (22\%) children and sulfadoxine-pyrimethamine remained the drug of choice (103/192, 54\%). Programmatic activities such as in-service training and provision of job aids did not seem to influence the prescribing of artemether with lumefantrine. Conclusion Although the use of chloroquine for uncomplicated malaria was succesfully discontinued in Zambia, the change of drug policy towards artemether-lumefantrine does not necessarily translate into adequate use of this drug at the point of care.
\end{abstract}

\section{Introduction}

The incidence of fatal Plasmodium falciparum infections has been increasing in Africa since the early 1990s, coincidental with the rapid expansion of resistance to first line therapies. ${ }^{12}$ Chloroquine was the basis of malaria treatment in Africa, but since the 1980s its clinical efficacy has precipitously declined, ${ }^{3}$ and sulfadoxine-pyrimethamine has had a short useful therapeutic life. ${ }^{3-5}$ Artemisinin based combination therapy has proved highly efficacious in Africa ${ }^{6-9}$ and is now recognised as the therapy of choice for countries with failing monotherapies.
By 2002 in Zambia overwhelming evidence showed that chloroquine was failing to cure over $50 \%$ of patients by day $14 .^{10-12}$ Furthermore, by 2003, sulfadoxine-pyrimethamine was failing in $8-33 \%$ of patients. ${ }^{12}{ }^{13}$ In December 2002, after a series of meetings, the Zambian Ministry of Health announced that chloroquine would be replaced as the first line therapy for uncomplicated malaria by artemether-lumefantrine for patients weighing $10 \mathrm{~kg}$ or more, and by sulfadoxine-pyrimethamine in children weighing less than $10 \mathrm{~kg}$ until more information on the efficacy and safety of artemether-lumefantrine became available in this patient group. It was also specified that in facilities where artemether-lumefantrine was not yet available, sulfadoxinepyrimethamine would be recommended first line treatment for all categories of patients. ${ }^{14}$

Changing and implementing new drug policies is complex when the transition includes familiar drugs that are commonly prescribed in a country, are easy to administer, are inexpensive, and are readily available. ${ }^{15}{ }^{16}$ Zambia was the first African country to change its policy towards using more expensive artemetherlumefantrine, characterised by a complex dosing regimen, complicated procurement and distribution, and little national prescribing experience. We describe treatment practices in Zambian children during the transition from chloroquine to artemether-lumefantrine and to sulfadoxine-pyrimethamine and examine the factors influencing the prescribing of artemether-lumefantrine.

\section{Methods}

We purposively selected four districts representing the major malaria ecologies of Zambia: Chingola, an urban district in the hypoendemic and mesoendemic areas of Copperbelt Province; Kalomo, a semi-arid district in the mesoendemic area of Southern Province; Chipata, a mixed rural and urban district of mesoendemic and hyperendemic transmission in Eastern Province; and Samfya, a rural, swampy, hyperendemic district of Luapula Province. The government decided on a phased introduction of artemether-lumefantrine, beginning in February 2003 with seven districts and expanding to 28 of 72 districts by the end of 2003. The surveyed districts were part of these 28 districts. Kalomo was also one of the seven early implementation districts. In these seven districts most of the stocks ran out by May 2003 but were replenished at the time of the regular supply to the 28 districts in December 2003, just before our study.

\section{Survey design and data collection}

We carried out a cross sectional cluster survey at all government and mission facilities in each district between 28 January and 19 March 2004. A cluster was defined as all sick children seen at a 
health facility during one day. We observed health workers' outpatient case management practices for children aged less than 5 years. The consultations were observed over one day at each facility. After the health worker and caretaker (usually the child's mother) provided informed consent, a surveyor enrolled all children presenting to the outpatient departments. If more than one health worker saw children at a facility, all were observed and interviewed.

Four teams each comprising three surveyors collected the data using four methods. Firstly, a surveyor observed the consultations and recorded the carrying out of clinical tasks, the child's main problems, and the duration and timing of consultations. Secondly, caretakers were interviewed before leaving the facility. Interviewers collected information on the child's age, history of fever, and if the visit was an initial or follow-up consultation. Information was collected from patient held records about diagnostic procedures requested and results reported, drugs prescribed, and if the child was treated as an outpatient or referred for admission to hospital. During interviews the child was weighed and his or her axillary temperature measured. Thirdly, the health workers were interviewed to collect information on their personal characteristics, work experience, and exposure to guidelines, training, and supervision. Fourthly, the health facility was assessed for availability of antimalarial drugs and malaria treatment wall charts.

\section{Definitions}

Our definitions reflect recommendations from the Zambian national guideline on the diagnosis and treatment of malaria. ${ }^{14}$ According to the guideline any child with fever or a history of fever in the absence of signs of severe malaria is presumed to have uncomplicated malaria. The guideline is ambiguous on the interpretation of malaria smear results and states that the "presence of signs and symptoms of disease with negative blood smear does not preclude the diagnosis of malaria." We defined a case of uncomplicated malaria as a child presenting to a health facility for an initial visit with a history of fever during the present illness or with an axillary temperature of $37.5^{\circ} \mathrm{C}$ or more, and treated as an outpatient in the absence of a routine negative blood slide result. We excluded from the analysis children with negative blood slide results to prevent health worker practices from being judged as incorrect owing to the ambiguity of the guideline. Recommended treatment for uncomplicated malaria was defined as a prescription forartemether-lumefantrine for children weighing $10 \mathrm{~kg}$ or more and a prescription for sulfadoxine-pyrimethamine for children weighing less than $10 \mathrm{~kg}$.

\section{Statistical analysis}

Data were double entered and verified using Microsoft Access 2000. An investigator corrected errors identified by the verification programme after referring to original questionnaires. The analysis was carried out using STATA, version 8 . We estimated the precision of proportions $(95 \%$ confidence intervals) accounting for the cluster sampling design by using "health facility day" as the primary sampling unit.

To identify predictors of prescriptions for artemetherlumefantrine in children weighing $10 \mathrm{~kg}$ or more with uncomplicated malaria, we used logistic regression modelling with the STATA xtgee procedure using an exchangeable working correlation matrix. ${ }^{17}$ This procedure uses generalised estimating equations to account for correlated data. We restricted the analysis to children with an antimalarial drug prescribed at facilities with available artemether-lumefantrine because we were interested in identifying factors that influenced the selection of this drug. In the univariate analysis, we estimated the odds ratio, $\mathrm{P}$ value, and 95\% confidence interval for the association between health workers' choice to prescribe artemether-lumefantrine and the factors associated with health facilities and health workers. In addition we tested the following child or consultation factors: duration and timing of consultation, starting time of the consultation, child's age, whether the child was weighed, whether the temperature was measured, the child's temperature, and the child's main problem. We evaluated 11 logical two way statistical interactions either between factors of programmatic importance such as in-service training, guidelines, wall charts, and supervision, or between the child's main problems. To avoid over fitting the model we presented only significant univariate results $(\mathrm{P}<0.05)$ and results for factors of particular programmatic importance. We used an $\alpha$ level of 0.05 for testing the hypothesis and for estimating the confidence intervals.

\section{Results}

We observed 1423 consultations among children aged less than 5 years seen by 103 health workers at 94 health facilities. No health worker or caretaker on behalf of the child refused to participate. Most health workers were nurses $(52 \%)$ or clinical officers (29\%; table 1). Most facilities were rural health centres $(83 \%)$, and most were run by the government $(92 \%)$. We analysed 1350 of 1423 consultations as 73 caretakers of observed children $(5.1 \%)$ had left the facility before the interview. Of these 1350 consultations, 944 children met our definition of uncomplicated malaria. The other 406 consultations were for follow-up visits, the child had neither a history of fever nor a temperature of $37.5^{\circ} \mathrm{C}$ or more, the child was referred for admission to hospital, or the child had negative blood slide results reported through routine practices. Of the 944 children with uncomplicated malaria, $550(58.3 \%)$ weighed less than $10 \mathrm{~kg}$; of these 550 children, $17(3.1 \%)$ had received sulfadoxine-pyrimethamine at home before coming to the facility.

\section{Antimalarial treatments for children with uncomplicated malaria}

Table 2 shows the antimalarial treatments for 944 children with uncomplicated malaria. In children weighing less than $10 \mathrm{~kg}$, national treatment recommendations were commonly followed: sulfadoxine-pyrimethamine was prescribed for $79.8 \%$ (439/ 550 ), only one child received chloroquine, and artemetherlumefantrine was rarely $(6 / 550,1.1 \%)$ prescribed. Of children weighing $10 \mathrm{~kg}$ or more, sulfadoxine-pyrimethamine was often used for treatment $(266 / 394,68 \%)$, no children were treated with chloroquine, and only $11 \%(42 / 394)$ of children were treated with artemether-lumefantrine. Overall, 16.6\% (157/944) of children left the facility with no antimalarial prescription.

We found no significant difference in artemetherlumefantrine use between Kalomo, the early implementation district, and the other three districts. In Kalomo, artemetherlumefantrine was prescribed for $10 \%$ (9/92) of children weighing $10 \mathrm{~kg}$ or more with uncomplicated malaria compared with 13\% (23/180) in Chipata, 7\% (6/88) in Samfya, and 12\% (4/34) in Chingola.

At facilities where artemether-lumefantrine was available on the day of the survey, the drug was prescribed by health workers for only $22 \%$ (42/192) of children weighing $10 \mathrm{~kg}$ or more, and sulfadoxine-pyrimethamine continued to be a preferred drug in this weight group (103/192, 54\%; table 2). Furthermore, health workers prescribed artemether-lumefantrine for only $18 \%$ (9/49) of children weighing $10 \mathrm{~kg}$ or more in Kalomo compared with $23 \%(33 / 143)$ in the other districts. 
Table 1 Characteristics of 94 health facilities and 103 health workers in four districts in Zambia

\begin{tabular}{|c|c|}
\hline Characteristics & No $(\%)$ of districts combined \\
\hline \multicolumn{2}{|l|}{ Health facilities } \\
\hline \multicolumn{2}{|l|}{ Type of facility: } \\
\hline Hospital affiliated health centre & $7(7.4)$ \\
\hline Urban health centre & $7(7.4)$ \\
\hline Rural health centre & $78(83.0)$ \\
\hline Health post & $2(2.1)$ \\
\hline \multicolumn{2}{|l|}{ Ownership: } \\
\hline Government & $86(91.5)$ \\
\hline Mission & $8(8.5)$ \\
\hline \multicolumn{2}{|l|}{ Equipment: } \\
\hline Weighing scale & $92(97.9)$ \\
\hline Thermometer & $91(97.8)^{*}$ \\
\hline Working microscope & $16(17.0)$ \\
\hline \multicolumn{2}{|l|}{ Wall charts: } \\
\hline Artemether-lumefantrine dosage & $19(20.2)$ \\
\hline Malaria recommended drugs & $2(2.1)$ \\
\hline Sulfadoxine-pyrimethamine dosage & $48(51.1)$ \\
\hline Chloroquine dosage & $11(11.7)$ \\
\hline Quinine dosage & $4(4.3)$ \\
\hline Integrated management of childhood illnesses & $5(5.3)$ \\
\hline \multicolumn{2}{|l|}{ Available drugs on survey day: } \\
\hline Artemether-lumefantrine (tablets) & $48(51.1)$ \\
\hline Sulfadoxine-pyrimethamine (any formulation) & $94(100)$ \\
\hline Quinine (injection) & $68(72.3)$ \\
\hline Quinine (tablets) & $74(78.7)$ \\
\hline Chloroquine (any formulation) & $71(75.5)$ \\
\hline \multicolumn{2}{|l|}{ Health workers } \\
\hline \multicolumn{2}{|l|}{ Pre-service training: } \\
\hline Clinical officer & $30(29.1)$ \\
\hline Enrolled nurse & $49(47.6)$ \\
\hline Registered nurse & $4(3.9)$ \\
\hline Nursing aid & $20(19.4)$ \\
\hline \multicolumn{2}{|l|}{ In-service training on malaria: } \\
\hline Artemether-lumefantrine $\dagger$ & $26(25.2)$ \\
\hline Integrated competency based & $7(6.8)$ \\
\hline Integrated management of childhood illnesses & $32(31.1)$ \\
\hline Other malaria & $16(15.5)$ \\
\hline Any including malariał & $62(60.2)$ \\
\hline \multicolumn{2}{|l|}{ Possession of guideline: } \\
\hline National malaria guideline & $60(58.3)$ \\
\hline Integrated technical guideline§ & $64(62.1)$ \\
\hline $\begin{array}{l}\text { Integrated management of childhood illnesses } \\
\text { guideline§ }\end{array}$ & $17(16.5)$ \\
\hline \multicolumn{2}{|l|}{ Frequency of supervision (past 6 months): } \\
\hline 0 visits & 14 (13.6) \\
\hline 1 or 2 visits & $64(62.1)$ \\
\hline$\geq 3$ visits & $25(24.3)$ \\
\hline
\end{tabular}

*Denominator does not include one observation with missing value.

†Process of cascade in-service training began with three subnational training of trainers then district level trainings. Training focused on artemether-lumefantrine treatment but also

included rationale for policy change, basic principles of malaria and its clinical presentation, malaria diagnosis, and management of uncomplicated and severe malaria. In addition, health workers from Kalomo district received supplementary training, alongside initial distribution of artemether-lumefantrine as part of early implementation in seven districts.

†Health workers who received at least one of above listed in-service trainings.

$\S$ These two guidelines were used before policy change and only latest editions were revised to include artemether-lumefantrine; survey was, however, unable to differentiate between editions.

\section{Readiness to deliver artemether-lumefantrine}

Of 103 health workers, $62(60 \%)$ had received in-service training that included the case management of malaria (table 1 ). Only 26 $(25 \%)$, however, had received training in artemetherlumefantrine, and more commonly in Kalomo (12/25, 48\%) than in Chipata (3/36, 7\%), Samfya (10/25, 37\%), or Chingola $(1 / 10,10 \%)$. Yet $60(58 \%)$ health workers possessed the national malaria guideline. Weighing scales were available in 92 of the 94 facilities (98\%) whereas wall charts showing dosages for artemether-lumefantrine were displayed in 19 (20\%), more commonly in Kalomo (9/24, 38\%) than in Chipata (6/36, 17\%), Samfya $(4 / 25,16 \%)$, or Chingola $(0 / 9,0 \%)$. Artemether-lumefantrine was available in $48(51 \%)$ facilities, with a higher availability in Kalomo (15/24, 63\%) and Chingola (7/9, 78\%) than in Chipata $(16 / 36,44 \%)$ and Samfya (10/25, 40\%). Conversely, sulfadoxinepyrimethamine was universally available, and oral quinine and chloroquine were available at $74(79 \%)$ and $71(76 \%)$ facilities, respectively.

\section{Predictors of artemether-lumefantrine prescriptions}

We examined 26 factors and 11 interaction terms that we hypothesised may have influenced the prescribing of artemether-lumefantrine in 151 children weighing $10 \mathrm{~kg}$ or more with uncomplicated malaria who were prescribed an antimalarial at facilities where artemether-lumefantrine was available. On univariate analysis, the following factors were significantly associated with the outcome that a child received a prescription for artemether-lumefantrine: child aged 2 or more years (odds ratio $3.00,95 \%$ confidence interval 1.29 to 6.97 ), consultation length seven or more minutes $(2.69,1.26$ to 5.76$)$, and treatment provided at health centres compared with hospitals $(8.69,1.28$ to 58.84). Children presenting with a skin problem were significantly less likely to be prescribed artemether-lumefantrine $(0.37,0.16$ to 0.86$)$. In-service training on artemether-lumefantrine, presence of artemetherlumefantrine wall charts, and possession of the guideline were not significantly associated with prescribing artemetherlumefantrine (table 3).

\section{Discussion}

The policy shift in Zambia in 2003 away from chloroquine as a first line therapy for uncomplicated malaria has been successfully implemented. Although the discontinuation of chloroquine was immediate, most clinicians opted for the more familiar sulfadoxine-pyrimethamine rather than the recently introduced artemether-lumefantrine. Although chloroquine was commonly in stock, it was almost never $(0.1 \%)$ used. This result represents a major improvement in the management of paediatric malaria. However, $17 \%$ of children meeting the definition of uncomplicated malaria received no antimalarial, a finding consistent with a report from Kenya. ${ }^{18}$ A possible explanation may be that the guideline based concept that equates all fevers with malaria is not accepted for all categories of children-that is, children with another obvious cause of fever. Children were rarely prescribed (22\%) artemether-lumefantrine at facilities with available stocks. Interestingly, compared with the other three districts, use of artemether-lumefantrine was equally low in Kalomo, which had more favourable readiness to deliver artemether-lumefantrine, and where, although short lasting, there was experience with the drug.

\section{Predictors of artemether-lumefantrine prescriptions}

Although our study had small power to detect differences in effect, several interesting findings resulted from our analysis of the predictors of correct prescribing. Provision of programmatic interventions such as in-service training and job aids did not seem to influence artemether-lumefantrine use. This finding was not surprising, and previous studies with a similar design suggested variously that in-service training either improved treatment practices ${ }^{19}$ had no association with performance, ${ }^{20}{ }^{21}$ or had an effect only in subgroups of health workers. ${ }^{18}$ The sys- 


\begin{tabular}{|c|c|c|c|c|c|c|}
\hline \multirow[b]{2}{*}{ Health facilities } & \multicolumn{2}{|c|}{ Bodyweight <10 kg } & \multicolumn{2}{|c|}{ Bodyweight $\geq 10 \mathrm{~kg}$} & \multicolumn{2}{|c|}{ Total } \\
\hline & No $(\%)$ & $95 \% \mathrm{Cl}$ & No $(\%)$ & $95 \% \mathrm{CI}$ & No $(\%)$ & $95 \% \mathrm{CI}$ \\
\hline All facilities: & \multicolumn{2}{|c|}{$\mathrm{n}=550$} & \multicolumn{2}{|c|}{$\mathrm{n}=394$} & \multicolumn{2}{|c|}{$\mathrm{n}=944$} \\
\hline Sulfadoxine-pyrimethamine & 439 (79.8) & 73.8 to 85.9 & $266(67.5)$ & 58.8 to 76.2 & $705(74.7)$ & 68.4 to 81.0 \\
\hline Artemether-lumefantrine & $6(1.1)$ & 0 to 2.6 & $42(10.7)$ & 5.4 to 16.0 & $48(5.1)$ & 2.6 to 7.5 \\
\hline Quinine & $14(2.6)$ & 0.8 to 4.3 & $19(4.8)$ & 2.0 to 7.6 & $33(3.5)$ & 1.8 to 5.2 \\
\hline Chloroquine & $1(0.2)$ & 0 to 0.5 & 0 & NA & $1(0.1)$ & 0 to 0.3 \\
\hline No antimalarial prescribed & $90(16.4)$ & 10.7 to 22.0 & $67(17.0)$ & 11.7 to 22.3 & $157(16.6)$ & 11.9 to 21.4 \\
\hline $\begin{array}{l}\text { Facilities with artemether-lumefantrine in } \\
\text { stock: }\end{array}$ & \multicolumn{2}{|c|}{$\mathrm{n}=262$} & \multicolumn{2}{|c|}{$\mathrm{n}=192$} & \multicolumn{2}{|c|}{$\mathrm{n}=454$} \\
\hline Sulfadoxine-pyrimethamine & $189(72.1)$ & 61.1 to 83.1 & $103(53.7)$ & 39.7 to 67.6 & $292(64.3)$ & 53.2 to 75.4 \\
\hline Artemether-lumefantrine & $6(2.3)$ & 0 to 5.7 & $42(21.9)$ & 12.4 to 31.3 & $48(10.6)$ & 6.1 to 15.1 \\
\hline Quinine & $9(3.4)$ & 0.3 to 6.6 & $6(3.1)$ & 0.4 to 5.9 & $15(3.3)$ & 1.0 to 5.6 \\
\hline No antimalarial prescribed & $58(22.1)$ & 11.8 to 32.5 & 41 (21.4) & 12.7 to 30.0 & $99(21.8)$ & 13.0 to 30.6 \\
\hline
\end{tabular}

Table 3 Univariate analysis of association between factors of programmatic importance and prescription of artemether-lumefantrine in children with uncomplicated malaria

\begin{tabular}{|c|c|c|c|c|}
\hline Factor & No of consultations & $\begin{array}{l}\text { No (\%) prescribed } \\
\text { artemether-lumefantrine }\end{array}$ & Odds ratio $(95 \% \mathrm{CI})$ & $P$ value \\
\hline \multicolumn{5}{|c|}{$\begin{array}{l}\text { Health worker received in-service training on } \\
\text { artemether-lumefantrine: }\end{array}$} \\
\hline Yes & 24 & $6(25)$ & 0.89 (0.24 to 3.30$)$ & 0.866 \\
\hline No & 127 & $36(28)$ & 1.0 & \\
\hline \multicolumn{5}{|c|}{ Artemether-lumefantrine wall chart in consultation room: } \\
\hline Yes & 45 & $12(27)$ & $0.81(0.28$ to 2.36$)$ & 0.705 \\
\hline No & 106 & $30(28)$ & 1.0 & \\
\hline \multicolumn{5}{|c|}{ Health worker had national malaria guideline: } \\
\hline Yes & 93 & $30(32)$ & 1.69 (0.41 to 4.21$)$ & 0.323 \\
\hline No & 58 & $12(21)$ & 1.0 & \\
\hline
\end{tabular}

tematic reviews of interventional trials published by the World Health Organization ${ }^{22}$ and those presented by Ross-Degnan et al (international conference on improving use of medicines, Chiang Mai, Thailand, 1997) found mixed results for training. These reviews describe other interventions that may improve use of medicines in developing countries, such as group processes, supervision, and performance monitoring using audit and feedback. One strategy that consistently failed to achieve improvements in most studies was the isolated dissemination of clinical guidelines, ${ }^{22}$ and our observations concur with these findings.

Aside from the potentially low impact of programmatic interventions, other factors might be responsible for low use of artemether-lumefantrine. The presence of a study observer could modify usual clinical practices (Hawthorn effect), however this effect is almost always in the direction of better performance. $^{23}$ Therefore although this bias may have led to an underestimation of chloroquine use, it is unlikely to explain the low use of artemether-lumefantrine. Our study was not designed to capture subtle health worker perceptions, but the reluctance to prescribe artemether-lumefantrine may reflect health worker concerns about drug potency, side effects, or concerns about interruptions to the stock, which might have led to discriminate treatment for only some categories of patients. For example, the significantly lower use of artemether-lumefantrine among children aged less than 2 years might reflect the concern that artemether-lumefantrine is "too strong" for very young children. Understanding such potential misperceptions and concerns should be a high research priority for Zambia, and perhaps other countries in the process of implementing artemisinin based combination therapy.

\section{Conclusion}

Lessons learnt from Zambia have important implications for other countries that have changed their malaria treatment policy but are yet to fully implement it. Deciding on a new drug policy is arguably the easy part of a complex process of policy changethe greatest challenge remains in changing clinical practices. Although a sustainable supply of expensive artemisinin based combination therapies is urgently needed across Africa, this must be accompanied by similar investments in effective interventions to ensure swift implementation and proper use of drugs at the point of care.

We thank the field teams, health workers, children, and caretakers; the data entry clerks Rodney Katango and Christine Mwape; Michael Macdonald, Mubiana Macwan'oi, Naawa Sipilanyambe, Pascalina Chanda, Mike English, and Jon Simon for comments on earlier drafts. RWS is a senior Wellcome Trust fellow (No 058992) and acknowledges the support of the Kenyan Medical Research Institute. This paper is published with the permission of the director of the Kenya Medical Research Institute.

Contributors: DZ and MN coordinated the survey design, trained the survey staff, were responsible for the analysis and drafted and completed the manuscript. DMT and DHH participated in the data analysis and drafting of the manuscript. AKR and RWS participated in the study design, analysis, and finalisation of the manuscript. DZ is the guarantor.

Funding: Zambian-Boston University Malaria Project (Association of Schools of Public Health and Centers for Disease Control and Prevention cooperation agreement S1954-21-21) and the Wellcome Trust, United Kingdom.

Competing interests: DZ and RWS have received a fee for speaking at a meeting organised by Novartis Pharma, the manufacturer of artemetherlumefantrine.

Ethical approval: This study was approved by the Boston University institutional review board (2003-412B) and research ethics committee of the University of Zambia (federal wide assurance No IRB00001131).

1 Snow RW, Trape JF, Marsh K. The past, present and future of childhood malaria mortality in Africa. Trends Parasitol 2001;17:593-7.

Korenromp E, Williams BG, Gouws E, Dye C, Snow RW. Measurement of trends in childhood malaria mortality in Africa: an assessment of progress toward targets based on verbal autopsy. Lancet Infect Dis 2003;3:349-58.

3 Talisuna AO, Bloland P, D'Alessandro U. History, dynamics and public health importance of malaria parasite resistance. Clin Microbiol Rev 2004;17:235-54. 


\section{What is already known on this topic}

Zambia was the first African country to change its antimalarial treatment policy to artemisinin based combination therapy (artemether-lumefantrine)

Changing clinical practice to support the change presents challenges

\section{What this study adds}

Most Zambian clinicians prescribe sulfadoxine-pyrimethamine rather than artemether-lumefantrine for children with uncomplicated malaria

Interventions such as in-service training and provision of job aids did not seem to influence the choice of artemether-lumefantrine

4 East African Network for Monitoring Antimalarial Treatment. The efficacy of antimalarial monotherapies sulphadoxine-pyrimethamine and amodiaquine in East Africa: implications for sub-regional policy. Trop Med Int Health 2003;8:860-7.

5 Myint HY, Tipmanee P, Nosten F, Day NPJ, Purkrittayakamee S, Looareesuwan S, et al. A systematic overview of published antimalarial drug trials. Trans R Soc of Trop Med Hyg 2004;98:73-81.

6 International Artemisinin Study Group. Artesunate combinations for treatment of malaria: meta-analysis. Lancet 2004;363:9-17.

7 Mutabingwa TK, Anthony D, Heller A, Hallett R, Ahmed J, Drakeley C, et al. Amodiaquine alone, amodiaquine+sulfadoxine-pyrimethamine, amodiaquine+ artesunate, and artemether-lumefantrine for outpatient treatment of malaria in Tanzanian children: a four-arm randomised effectiveness trial. Lancet 2005;365:1474-80.

8 Piola P, Fogg C, Bajunirwe F, Biraro S, Grandesso F, Ruzagira E, et al. Supervised versus unsupervised intake of six-dose artemether-lumefantrine for treatment of acute uncomplicated Plasmodium falciparum malaria in Mbarara, Uganda: a randomised trial. Lancet 2005;365:1467-73.

9 Falade C, Makanga M, Premji Z, Ortmann CE, Stockmeyer M, de Palacios PI. Efficacy and safety of artemether-lumefantrine (Coartem) tablets (six-dose regimen) in African infants and children with acute, uncomplicated falciparum malaria. Trans $R$ Soc of Trop Med Hyg 2005;99:459-67.

10 National Malaria Control Centre. National malaria situation analysis 2000. www.cboh.gov.zm/documents/

Copy $\% 20$ of $\% 20$ Final $\% 20$ Malaria $\% 20$ SA $\% 20$ Document $\% 202000$.pdf (accessed 1 Aug 2005).

11 Hamer DH, MacLeod W, Addo-Yobo E, Duggan CP, Estrella B, Fawzi WW, et al. Age, temperature, and parasite density predict chloroquine treatment failure in childre with uncomplicated falciparum malaria. Trans R Soc of Trop Med Hyg 2003;97:422-8.

12 Bijl HM, Kager J, Koetsier DW, van der Werf TS. Chloroquine-and sulfadoxinepyrimethamine-resistant falciparum malaria in vivo-a pilot study in rural Zambia. Trop Med Int Health 2000;5:692-5.
13 Chanda P, Sikaala CH, Kapelwa W, Moonga H, Njunju E, MacDonald M, et al. Decreasing efficacy of sulphadoxine-pyrimethamine (SP) in Zambian children. Proceedings of the 53rd annual meeting of the American Society of Tropical Medicine and Hygiene. Miami, USA. Am J Trop Med Hyg 2004;71(4) suppl:abstract 708.

14 Central Board of Health. Guidelines for the diagnosis and treatment of malaria in Zambia. A Production of the RBM Partnership in Zambia. Lusaka, Zambia: CBoH, 2003.

15 Shretta R, Omumbo J, Rapuoda B, Snow RW. Using evidence to change antimalarial drug policy in Kenya. Trop Med Int Health 2000;6:755-64.

16 Williams HA, Durrheim D, Shretta R. The process of changing national malaria treatment policy: lessons from country-level studies. Health Policy Plan 2004;19:356-70.

17 Horton NJ, Lipsitz SR. Review of software to fit generalized estimating equation regression models. Am Stat 1999;53:160-9.

18 Zurovac D, Rowe AK, Ochola SA, Noor AM, Midia B, English M, et al. Predictors of the quality of health worker treatment practices for uncomplicated malaria at government health facilities in Kenya. Int J Epidemiol 2004:33:1080-91.

19 Naimoli J. Theoretical and empirical advances in research on the implementation of an integrated approach to managing childhood illness in outpatient facilities in developing countries. [Doctoral dissertation.] Cambridge, MA: Harvard School of Public Health, 2001

20 Rowe AK, Hamel MJ, Flanders WD, Doutizanga R, Ndoyo J, Deming MS. Predictors of correct treatment of children with fever seen at outpatient health facilities in the Central African Republic. Am J Epidemiol 2000;151:1029-35.

21 Rowe AK, Onikpo F, Lama M, Deming MS. Risk and protective factors for two types of error in the treatment of children with fever at outpatient health facilities in Benin. Int J Epidemiol 2003;32:296-303.

22 World Health Organization. Interventions and strategies to improve the use of antimicrobials in developing countries. WHO/CDS/CSR/DRS/2001.9. Geneva: WHO, 2001.

23 Rowe AK, Lama M, Onikpo F, Deming MS. Health worker perceptions of how being observed influences their practices during consultations with ill children. Trop Doct 2002;32:166-7.

\section{(Accepted 18 August 2005)}

bmj.com 2005;331:734

Malaria Public Health and Epidemiology Group, Centre for Geographic Medicine, KEMRI/Wellcome Trust Collaborative Programme, PO box 43640, 00100 GPO, Nairobi, Kenya

Dejan Zurovac clinical research officer

Chainama Hills College Hospital of Health Sciences, Lusaka, Zambia Mickey Ndhlovu clinical research officer

Malaria Branch, Division of Parasitic Diseases, National Center for Infectious Diseases, Centers for Disease Control and Prevention, Atlanta, Georgia 30341, USA

Alexander K Rowe medical epidemiologist

Center for International Health and Development, Boston University School of Public Health, Boston, MA 02118, USA

Davidson H Hamer associate professor

Donald M Thea professor

Malaria Public Health and Epidemiology Group, Centre for Geographic Medicine,

KEMRI/Wellcome Trust Collaborative Programme

Robert W Snow professor

Correspondence to: D Zurovac dzurovac@wtnairobi.mimcom.net 